\title{
Diagnosis and Evaluation of Hypertension Control in Dakar: Role of Ambulatory Blood Pressure Measurement
}

\author{
Fatou Aw Leye ${ }^{1 *}$, Bodian $\mathbf{M}^{1}$, Akanni $S^{1}$, Bathily C Sarr SA ${ }^{1}$, Mingou JS ${ }^{1}$, Affangla $A^{4}$, Diouf MT ${ }^{1}$, Ndiaye M Diop \\ $\mathrm{CMBM}^{1}$, Ndiaye $\mathrm{PN}^{1}$, Balde $\mathrm{DW}^{1}$, Ngaïdé $\mathrm{AA}^{2}$, Dioum $\mathrm{M}^{3}$, Leye $\mathrm{M}^{4}$, Ndiaye $\mathrm{MB}^{1}, \mathrm{Mbaye}^{3}$, Kane Ad ${ }^{5}, \mathrm{Kane}^{6}, \mathrm{Diao}^{1}$ \\ and Serigne Abdou BA ${ }^{1}$
}

${ }^{1}$ Cardiology Department, Teaching Hospital Aristide Le Dantec, Senegal

${ }^{2}$ Cardiology Department, General Hospital of Grand Yoff, Senegal

${ }^{3}$ Cardiology Department, National Teaching Hospital of Fann, Senegal

${ }^{4}$ Training and research unit of Thies, Sénégal

${ }^{5}$ Cardiology Department of regional hospital of Saint Louis, Senegal

${ }^{6}$ Cardiology Department of Dalal Jamm hospital, Dakar Senegal

*Corresponding author: Fatou Aw Leye, Cardiology service of the Aristide Le Dantec University Hospital Center, P0 Box 6003 Dakar Etoile, Senegal

\begin{abstract}
Introduction: Hypertension is a major public health problem in Sub-Saharan Africa. Current recommendations place particular emphasis on ambulatory measures compared to clinical ones for the diagnosis and monitoring of treated hypertensive patients. This is how we conducted this study which aims to assess the contribution of ambulatory blood pressure measurement (ABPM) in our practice.

Materials and methods: This was a descriptive cross-sectional study carried out at the cardiology department of the Aristide Le Dantec teaching hospital over a period of twelve (12) months (January 1, to December 31, 2018).

Results: We collected 122 patients during the study period, with a female predominance (M / F sex ratio $=0.69)$. The average age of the population was $53.22 \pm 13.19$ years.

The indication for ABPM was a therapeutic evaluation in 81 patients (66.40\%), with a diagnostic aim of hypertension for 41 patients (33.60\%) including 5 cases of Pregnancy-induced hypertension. ABPMs were normal in 30\% of cases. The nycthemeral average was $140 \pm 18.66$ for systolic blood pressure and $84.02 \pm 14.56$ for diastolic blood pressure. Among the abnormal measures, we noted $45.90 \%$ of dipper subjects, and $41 \%$ of non-dippers. In the therapeutic evaluation, hypertension was controlled in 22 patients $(27.2 \%)$ and uncontrolled in 59 cases $(72.80 \%)$. In the diagnostic indication, hypertension was confirmed in 23 cases $(63.9 \%)$ and a white coat hypertension was found in 13 cases (36.1\%). Pregnancy-induced hypertension was confirmed in 3 out of 5 patients $(60 \%)$.

Conclusion: This study showed the importance of ABPM as a diagnostic and therapeutic evaluation tool. Its rational use in our context would improve the care of hypertensive patients and thus prevent damage to target organs.
\end{abstract}

Keywords: Hypertension; ABPM; blood pressure control

\section{Introduction}

Hypertension is a common chronic disease representing a major public health problem. In 2000, it reached one out of four adults worldwide, ie a rate of $26.5 \%$, with an evolution in prevalence

which should reach $29 \%$ in 2025 [1]. In Africa, more than $40 \%$ of the adult population is affected, and this prevalence varies according to the country [2]. In Senegal, it affects one out of three Senegalese, ie 
3 million Senegalese [3], with an estimated prevalence of $29 \%$ in people aged 18 to 69 years [4]. However, despite the seriousness of hypertension, correct treatment and good control of blood pressure figures significantly reduce the risk of cardiovascular complications. Compared to the blood pressure measurement at the medical office, the ambulatory blood pressure measurement for 24 hours reflects more accurately the patient's blood pressure to which he is subjected in his real life conditions [5]. This examination is more correlated with the evaluation of the cardiovascular risk and the damage to the target organs than the clinical measurement and makes it possible to find certain phenomena such as hypertension called "white coat", masked hypertension or anomalies of the circadian rhythm of blood pressure (BP). We therefore carried out a study, whose aim was to assess the contribution of ABPM in the diagnosis and evaluation of the level of control of hypertension, in the cardiology department of Aristide le Dantec Hospital.

\section{Patients and Methods}

We carried out a cross-sectional, descriptive study with data collection carried out over 12 months (January 1 to December 31, 2018) in the cardiology department of Aristide Le Dantec Hospital in Dakar. This study included all patients who benefited from an ABPM in the department, in the context of suspected hypertension or a therapeutic evaluation, and who consented to participate in the study. Invalid ABPMs (lasting less than 24 hours or less than 50 good measurements) were not included. The ABPMs were performed using a Meditech ABPM-05 brand device. Data collection and processing was carried out using HM5 software. Concerning the interpretation of the ABPM results, the reference values used are those of the meta-analysis by Staessen [6]:

a. A BP of more than $135 / 85 \mathrm{mmHg}$ was considered as the limen for confirming the diagnosis of hypertension, for the daytime averages.

b. Hypertension was considered to be controlled for a BP $<130 / 80 \mathrm{~mm} \mathrm{Hg}$ over the entire 24-hour average.

We studied the type of systolic, diastolic or systolo-diastolic hypertension. We analyzed the nycthemeral profile for: diurnal, nocturnal or both. Finally, we looked for the existence of a night dip. Were classically defined as 'non-dippers', patients who did not show a decrease in day and night blood pressure of at least 10/5 mmHg or at least $10 \%$ [7]. In contrast, subjects with nighttime BP drop values greater than $20 \%$ can be considered « extreme dippers »[8].

Patients were said to be "dippers" when their nocturnal BP decreased by 10 to $20 \%$. A lowering of more than $20 \%$ defined extreme dipper patients. Non-dipper patients had a decrease of less than $10 \%$ in their nocturnal systolic blood pressure. The dipper reversals had their nocturnal blood pressure figures higher than the daily figures. Pulse pressure was defined as the difference between systolic BP and diastolic BP [9]. In our study, we considered as high a pulsed pressure (PP) $\geq 60 \mathrm{mmHg}$ [9-11]: A white coat hypertension is defined by the presence of an hypertension during the consultation at the clinic that showed normal on the $24 \mathrm{~h}$ ambulatory measurement [8]. Masked hypertension is defined by the presence of normal blood pressure figures in the clinic and a high BP in ambulatory care. It is the opposite phenomenon of the white coat HT. Resistant hypertension or refractory hypertension is defined as persistent hypertension despite optimal antihypertensive triple therapy including a diuretic [8]. The data collected were entered using a questionnaire developed by Sphinx plus 5 software.

\section{Results}

A total of 122 patients were recruited during the study period. The average age of the population was $53.22 \pm 13.19$ years with extremes of 25 and 85 years. The female sex predominated with a sex ratio $\mathrm{M} / \mathrm{F}$ of 0.69 . The majority of the population had hypertension ranging from 1 year to 10 years. In our study, 81 patients were taking antihypertensive therapy, the majority of them on dual therapy (58\%). Physical inactivity (59.80\%), menopause $(68 \%)$ and diabetes $(36.88 \%)$ were the most common risk factors (Table 1).

Table 1: General characteristics of the studied patients.

\begin{tabular}{|c|c|c|}
\hline Characteristics & Effectif & Percentage (\%) \\
\hline Sex ratio Men/Women & 0.69 & - \\
\hline Median age & $\begin{array}{c}53,22 \pm 13,19 \text { (25 à } 85 \\
\text { ans) }\end{array}$ & - \\
\hline \multicolumn{3}{|c|}{ Risk factors : } \\
\hline Physical inactivity & $73(n=122)$ & 59,80 \\
\hline Diabetes & $45(n=122)$ & 36,90 \\
\hline Menopause & $49(n=72)$ & 68,05 \\
\hline Contraception & $15(\mathrm{n}=72)$ & 20 \\
\hline Tobacco & $31(n=122)$ & 60,2 \\
\hline Obesity & $21(n=117)$ & 32,8 \\
\hline \multicolumn{3}{|c|}{ Duration of hypertension: } \\
\hline Less than 1 year & $40(n=110)$ & 36,30 \\
\hline $1-10$ years & $47(n=110)$ & 42,50 \\
\hline $10-20$ years & $18(n=110)$ & 16,80 \\
\hline Greater than 20 years & $5(n=5)$ & 4,40 \\
\hline \multicolumn{3}{|c|}{ Therapeutic protocol : } \\
\hline Monotherapy & $20(n=81)$ & 24,70 \\
\hline Bitherapy & $47(n=81)$ & 58 \\
\hline Tritherapy & $14(\mathrm{n}=81)$ & 17,30 \\
\hline
\end{tabular}

In the diagnostic indication for high blood pressure, ABPM was normal in $36.1 \%$ of cases. We found 13 profiles simulating a white coat $\mathrm{HT}$, ie a rate of $36.1 \%$. Among them were nine female patients. ABPM was requested in $66.4 \%$ of cases for a therapeutic evaluation (Table 2). In the context of this therapeutic evaluation, $27.2 \%$ of the patients were well controlled. Resistant hypertension was found in $7.37 \%$ of cases. 
Table 2: Distribution of patients according to ABPM results.

\begin{tabular}{|c|c|c|}
\hline Parameters & Effectif & Percentage (\%) \\
\hline \multicolumn{3}{|l|}{ Indication } \\
\hline Diagnostic evaluation & 41 & 33,60 \\
\hline $\begin{array}{l}\text { Therapeutic } \\
\text { evaluation }\end{array}$ & 81 & 66,40 \\
\hline \multicolumn{3}{|c|}{ Nychtemeral profile } \\
\hline SP & $140 \pm 18,66 \mathrm{mmHg}$ & - \\
\hline DP & $84,02 \pm 15,56 \mathrm{mmHg}$ & - \\
\hline \multicolumn{3}{|c|}{ Average daytime } \\
\hline SP & $143,06 \pm 19,12 \mathrm{mmHg}$ & \\
\hline DP & $87,52 \pm 15,25 \mathrm{~mm} \mathrm{Hg}$ & \\
\hline \multicolumn{3}{|c|}{ Average nighttime } \\
\hline SP & $134,80 \pm 19,53 \mathrm{mmHg}$ & \\
\hline DP & $79,12 \pm 13,76 \mathrm{mmHg}$ & \\
\hline \multicolumn{3}{|c|}{ Type of hypertension } \\
\hline Systolic & $26(n=85)$ & 30,6 \\
\hline Diastolic & $4(n=85)$ & 4,7 \\
\hline Systolic and diastolic & $55(n=85)$ & 64,7 \\
\hline \multicolumn{3}{|c|}{ Dipping } \\
\hline Dipper & $56(n=122)$ & 45,9 \\
\hline No dipper & $50(n=122)$ & 41 \\
\hline Extrem dipper & $7(\mathrm{n}=122)$ & 5,7 \\
\hline Reverse dipper & $9(\mathrm{n}=122)$ & 7,4 \\
\hline $\begin{array}{l}\text { Abnormal pulse } \\
\text { pressure }\end{array}$ & $25(n=121)$ & 20,76 \\
\hline
\end{tabular}

$\mathrm{SP}$ : systolic pressure DP : diastolic pressure

\section{Discussion}

The average age of our patients was $53.22 \pm 13.19$ years. This result is higher than that found in the department in a study which found an average age of $49.6 \pm 11.5$ years [12]. There is a female predominance (59\%); similar results had been previously reported [12]. Analysis of the ABPM indications shows that it is mainly prescribed in the cardiology department of the Aristide Le Dantec Hospital to evaluate antihypertensive therapy (66.48\%). Of the 81 ABPMs, only 22 hypertensive patients were controlled, a rate of $27.20 \%$. This rate is far from satisfactory in comparison with the reported level of control from Brazzaville [13] estimated at $35 \%$. Our low control rate could be explained by the fact that only patients not controlled in the office had the prescription for ABPM. The control rate based on clinical measures in 1995 in Dakar was $32 \%$ [14]. In sub-Saharan Africa, the low levels of hypertension control are alarming [15]. Worldwide, good control of hypertension remains a real problem.

In our study, the diagnostic indication ranked second at 33.6\%. This has been observed in most studies, except in Ivory Coast [16]. where the indication for diagnosis of hypertension was in first place with a percentage of $81.4 \%$, and the indication for therapeutic evaluation came in second place with a rate of $4.3 \%$. Of the 41 patients referred for a diagnostic review of hypertension, HT was confirmed in $70.8 \%$ of cases. The ESH / ESC 2018 working group recommends that the diagnosis of hypertension be based on an ambulatory blood pressure measurement (Holter blood pressure) and /or on self-measurements, provided that they are logistically and economically feasible [17]. According to a study [18]. on ABPM in the diagnosis of hypertension: neither the clinical measurements, nor the home measurements had sufficient sensitivity or specificity to be recommended as a single diagnostic test.

The white coat hypertension was observed in 13 patients (36.1\%). In Brazzaville, $25 \%$ of patients with suspected hypertension had a normal blood pressure profile [13]. These results are consistent with data from the 2013 ESH / ESC recommendations [19], which indicate an average prevalence of white coat hypertension between 13 and $32 \%$.

The prognosis for patients having a white coat HT is a topic of discussion. Ugajin and Co [20]. demonstrated, over an 8-year follow-up, that patients with white coat hypertension became hypertensive in $47 \%$ of cases, compared to $22 \%$ of patients initially normotensive $(\mathrm{p}<0.001)$.

In this work, the proportion of non-dipping subjects on the whole population was estimated at $54.10 \%$. The extreme dippers patients were $5.70 \%$. Indeed, Kario and Co have shown that these "extreme dippers" patients have advanced silent brain damage detected by MRI [13], and the JMS-ABPM study wave 1 also showed that elderly hypertensive patients and "extreme dippers "presented more cerebrovascular events [21]. In addition to the diagnostic and therapeutic evaluation role, ABPM also allows a prognostic evaluation. The pejorative nature of hypertension is reflected by the level of pulsed pressure which is well correlated with cardiovascular morbidity and mortality.

In our series, the rate of pulse pressure (PP) greater than or equal to $60 \mathrm{mmHg}$ was $20.70 \%(\mathrm{n}=25)$. Madhavan and Co have shown that the PP alone, not diastolic and systolic BP, is a predictor of myocardial infarction [11, 22].

Accumulated data suggest that monitoring ambulatory blood pressure is a better prognostic marker than clinically obtained blood pressure. Outpatient blood pressure monitoring can detect white coat hypertension and masked hypertension, which reduces the risk of misclassification of blood pressure [23-26]. The main limitation of the study was the accessibility of the device. In fact, we had at our disposal only one ABPM device in the cardiology department. This explains the relatively small sample size.

\section{Conclusion}

ABPM is an important and very useful tool that should occupy a privileged place in diagnosis and therapeutic evaluation. Its rational use in our context should allow the improvement of the management of hypertensive patients and facilitate the prevention of HT complications. 


\section{References}

1. Kearney PM, Whelton M, Reynolds K (2005) Global burden of hypertension: analysis of worldwide data. The lancet 365(4955) :277223.

2. OMS, organisation mondiale de la santé (2014) Statistique Sanitaire mondiale.

3. Kane A (2015) Hypertension artérielle de l'adulte: du diagnostic à la prise en charge thérapeutique. Presse Universitaire de Dakar pp. 135.

4. Etudes Steps Sénégal (2016) Enquête nationale sur les facteurs de risque des maladies non transmissibles. ANSD p. 69.

5. Pechère Bertschi A, Michel Y, Brandstatter H, Muggli F, Gaspoz J (2009) Lecture de la mesure ambulatoire de la pression artérielle (MAPA) par le médecin de premier recours. Rev Med Suisse 5: 1876-1880.

6. Steassen JA, Faguard RH, Lignen RH (1991) Mean and range of the ambulatory pressure in normotensive subjects from a meta-analysis of 23 studies. Am J Cardiol 67: 723-727.

7. O'Brien E, Sheridan J, O'Malley K (1988) Dippers and non-dippers. Lancet 2: 397.

8. Baguet JP, Barone Rochette G, Mallion JM (2007) Mesure ambulatoire de la pression artérielle. EMC - Cardiologie 2(2): 1-8.

9. Manzo Silberman S, Safar M, Blacher J (2010) Pression artérielle pulsée. EMC - Cardiologie 5(2): 1-5.

10. Benetos A, Safar M, Rudnichi A (1997) Pulse pressure: a predictor of long- term cardiovascular mortality in a French male population. Hypertension 30: 1410-1415.

11. Madhavan S, O'oi WL, Cohen H (1994) Relation of pulse pressure and blood pressure reduction to the incidence of myocardial infarction. J Hypertension 23: 395-401.

12. Aw F, Sarr S, Mingou J, Balde M, Bodian M, et al. (2018) Indications et résultats de la mesure ambulatoire de pression artérielle au service de cardiologie de l'hôpital Aristide le Dantec. Mali Médical. TOME XXXIII (4): 26-30.

13. Ikama MS, Nsitou BM, Makani J (2015) Arterial hypertension and control in Brazzaville (Congo): Role of ambulatory blood pressure monitoring (ABPM)]. Ann Cardiol Angeiol (Paris) 64(2): 76-80.

14. Kane A, Ba SA, Sarr M (1995) Hypertension artérielle au Sénégal: aspects épidémiologiques, cliniques et problèmes de la prise en charge thérapeutique. Dakar Méd 40(2): 157-161.
15. Hendriks ME, Wit FW, Roos MT (2012) Hypertension in Sub-Saharan Africa: cross-sectional surveys in four rural and urban communities. Plos One 7(3): 326-338.

16. N'Guetta R, Adoh M, Anzouan-Kakou JB (2007) Indications et profil des médecins prescripteurs de la Mesure Ambulatoire de la Pression Artérielle à l'Institut de Cardiologie d'Abidjan. Med Afr Noire 54(1): 4145.

17. Williams B, Mancia G, Spiring W, Wilko Spiering, Enrico Agabiti Rosei et al. (2018) ESC/ESH Guidelines for the management of arterial hypertension. European Heart 39(33): 3021-3104.

18. Hodgkinson J, Mant J, Martin U (2011) Relative effectiveness of clinic and home blood pressure monitoring compared with ambulatory blood pressure monitoring in diagnosis of hypertension: systematic review. BMJ 342: d3621.

19. Mancia G, Faguard R, Narkiewiez K (2013) 2013 ESH/ESC Guidelines for the management of arterial hypertension: The Task Force for the Management of Arterial Hypertension of the European Society of Hypertension (ESH)and of the European Society of Cardiology (ESC). J Hypertens 31: 1281-357.

20. Ugajin T, Hozawa A, Ohkubo T, Asayama K, Kikuya M, et al. (2005) White-coat hypertension as a risk factor for the development of home hypertension: the Ohasama study. Arch Intern Med 165(13): 1541-46

21. Kario K, Pickering TG, Matsuo T (2001) Stroke prognosis and abnormal nocturnal blood pressure falls in older hypertensives. J Hypertension 38 : 852-857.

22. Fang J, Madhavan S, Cohen H (1995) Measures of blood pressure and myocardial infarction treated hypertensive patients. J Hypertens 13: 413-419.

23. Asmar R (1998) Mesure ambulatoire de la pression artérielle ou Holter tenssionnel semaine des hôpitaux de Paris 11: 607-611.

24. Agence de la santé publique du Canada. Faits et chiffres sur l'hypertension.

25. Stephan D, Gaertner S, Cordeanu EM (2017) Updated management of adult hypertension. Therapeutic Med 23: 21-28.

26. Yaméogo NV, Kagambèga LJ, Millogo RC, Kologo KJ, Yaméogo AA, et al. (2013) Factors associated with poor blood pressure control in hypertensive black Africans: cross-sectional study of 456 hypertensive patients from Burkina Faso. Ann Cardiol Angeiol. Paris 62(1): 38-42.

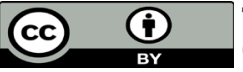

This work is licensed under Creative Commons Attribution 4.0 License

To Submit Your Article Click Here:

Submit Article
DOI: 10.32474/ACR.2020.02.000148

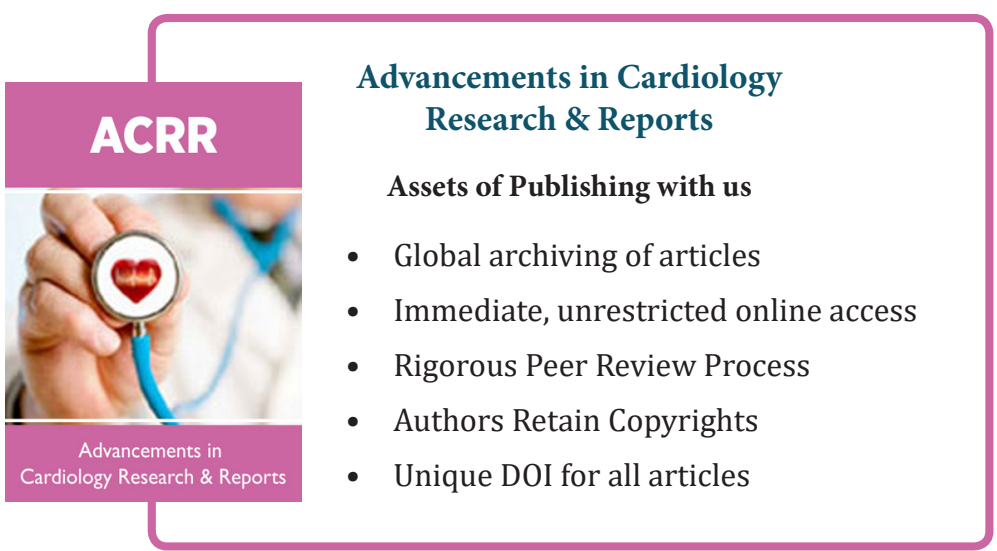

